\title{
ANALISA VARIASI UKURAN VENTURI KARBURATOR TERHADAP KONSUMSI BAHAN BAKAR PADA SEPEDA MOTOR YAMAHA RX-KING 135cc
}

\author{
Kurnia Dwi Artika, Yusuf Akbar \\ Jurusan Mesin Otomotif, Politeknik Negeri Tanah Laut \\ email: kurnia.2a@politala.ac.id
}

\begin{abstract}
ABSTRAK
Penggunaan sepeda motor saat ini mengalami peningkatan yang sangat pesat. Dampaknya adalah konsumsi bahan bakar yang juga meningkat. Teknologi sepeda motor semakin maju dan berkembang, dari mesin 2 tak menjadi 4 tak, dari sistem bahan bakar karburator menjadi injeksi. Sepeda motor RX-King masih menggunakan mesin 2 tak dan sistem karburator. Di dalam karburator terdapat lubang/pipa venturi yang pengaruhnya sangat besar terhadap putaran mesin dan konsumsi bahan bakar sesuai besarnya diameter venturi. Dari latar belakang tersebut, maka dapat dilakukan analisa pengaruh ukuran venturi terhadap konsumsi bahan bakar. Penelitian dilakukan dengan variasi ukuran venturi karburator 26,3 mm, 27,8 mm dan 28,8 mm dengan putaran mesin $4000 \mathrm{rpm}(54 \mathrm{~km} / \mathrm{jam})$ dan bahan bakar premium. Pengujian dilakukan dengan mengukur dan mencatat waktu dari konsumsi bahan bakar, kemudian menganalisa venturi standart, perbesaran dan pengecilan diameter venturi. Adapun hasil dari setiap diameter venturi karburator terhadap konsumsi bahan bakar adalah masing-masing venturi 26,3 mm adalah 8,48 menit, pada venturi 27,8 mm (standart) adalah 7,14 menit dan pada venturi 28,8 mm adalah 6,15 menit. Sehingga pengecilan diameter venturi karburator dapat mengurangi konsumsi bahan bakar 18,77\% tanpa mengurangi kinerja/performa kendaraan.
\end{abstract}

Kata Kunci: RX-King, bahan bakar, venturi, karburator, motor 2-tak.

\section{PENDAHULUAN}

Penggunaan sepeda motor di Indonesia saat ini sudah mengalami perkembangan yang sangat pesat, dilihat dari data Badan Pusat Statistik(BPS) Indonesia untuk pemakaian sepeda motor dari tahun ketahun paling banyak jumlah pemakaiannya dibandingkan alat transportasi darat yang lain, terhitung pada tahun 2013 terakhir pemakaiannya berjumlah 84.732 .652 tentunya semua itu akan berdampak pada tingkat konsumsi bahan bakar. Sepeda motor terbagi menjadi dua berdasarkan sistem kerja dan sistem percamburan bahan bakarnya yaitu sepeda motor 4 tak dan 2 tak. sepeda motor 4 tak saat ini yang paling banyak digunakan, karena sepeda motor jenis ini memiliki tingkat konsumsi bahan bakar yang rendah dibandingkan sepeda motor 2 tak Dikarenakan rata-rata sudah menggunakan injector sebagai sistem penyemprotan bahan bakar pada ruang bakarnya yang dikendalikan oleh ECU (elektronic control unit), pencampuran bahan bakar dan udara dapat stabil dan dikurangi seefisien mungkin, Tidak seperti sepeda motor 2 tak yang masih menggunakan karburator pada sistem pencamburan bahan bakarnya. Walaupun sepeda motor 2 tak terbilang boros bahan bakar namun masih ada orang yang memakainya dikarenakan tenaga yang dihasilkan sepeda motor 2 tak yang lebih cepat dibandingkan sepeda motor 4 tak. Sepeda motor dua tak memiliki performa dan tingkat responsif yang baik dikarenakan mesin 2 tak juga memanfaatkan area di bawah torak (crankcase) untuk mempercepat operasi. Tidak seperti motor 4 tak yang seluruh prosesnya berlangsung di atas torak [1]. Yamaha rx-king $135 \mathrm{cc}$ termasuk sepeda motor 2 tak yang memiliki performa dan tingkat resfonsif yang tinggi dan menggukan karburator sebagai transfer bahan bakarnya. Karburator memiliki komponen-komponen penting yang berpengaruh terhadap masuknya bahan bakar keruang silinder, venturi adalah bagian utama karburator sebagai jalan masuknya udara dan tempat tercampurnya bahan bakar maka ukuran venturi sangat berpengaruh terhadap konsumsi bahan bakar.

Diketahui Yamaha rx-king 135 cc adalah sepeda motor yang tingkat konsumsi bahan bakarnya tinggi untuk 1 liter bahan bakar hanya dapat menempuh jarak 25-30 km pada waktu masih dalam kondisi standart. Konsumsi bahan bakar yang berlebihan tersebut tentu sangat mengganggu terhadap para pemakai dan pencinta motor tersebut apalagi bagi yang suka melakukan perjalanan jauh menggunakan motor ini. Maka untuk mengetahui jumlah pemakaian bahan bakar dilakukan penelitian dengan pembesaran venturi serta pengecilannya dari ukuran standartnya. Dengan judul analisa variasi ukuran venturi karburator pada sepeda motor Yamaha rx-king 135 cc. Diharapkan tanpa mengurangi performa dan tingkat responsif dari motor tersebut dengan menggunakan karburator ukuran venturi $26 \mathrm{~mm}$ standard rx-king, 26 pembubutan dan 28 
mm. Adapun nantinya yang akan dianalisa adalah bagaimana pengaruh masing-masing ukuran venturi terhadap konsumsi bahan bakar sepeda motor Yamaha rx-king $135 \mathrm{cc}$.

\section{TINJAUAN PUSTAKA}

\section{Prinsip Kerja}

Motor dua langkah hanya membutuhkan satu kali putaran poros engkol untuk menyelesaikan satu siklus di dalam silinder. Kerja (langkah daya) dihasilkan pada setiap putaran crankshap. Motor dua langkah beroperasi tanpa katup. Sebagai pengganti katup, kebanyakan mesin 2 langkah menggunakan lubang saluiran di dinding silinder yang dibuka dan ditutup torak ketika bergerak naik turun didalam silinder. Beberapa motor 2 langkah menggunakan katup pasif atau kelopak penutup yang disebut katup buluh untuk membantu menutup bak crankshap setelah campuran udara/bahan bakar dihisap. Jika seluruh proses pada motor 4 langkah berlangsung diatas torak, maka motor 2 langkah juga memanfaatkan area dibawah torak (crankcase) untuk mempercepat oprasi. Proses kompresi pada motor 2 langkah terjadi dua kali setiap putaran. Kompresi pertama atau pre-compression berlangsung didalam ruang crankcase yang selanjutnya dikompresi melalui gerakan crankshap dan masuk keruang bakar. Kompresi kedua berlangsung didalam silinder dan ruangbakar sehingga dihasilkan tekanan tinggi untuk menyalakan campuran udara-bahan bakar dengan bantuan busi. Prinsip kerja dari mesin 2 langkah ditunjukan pada Gambar 1 berikut:

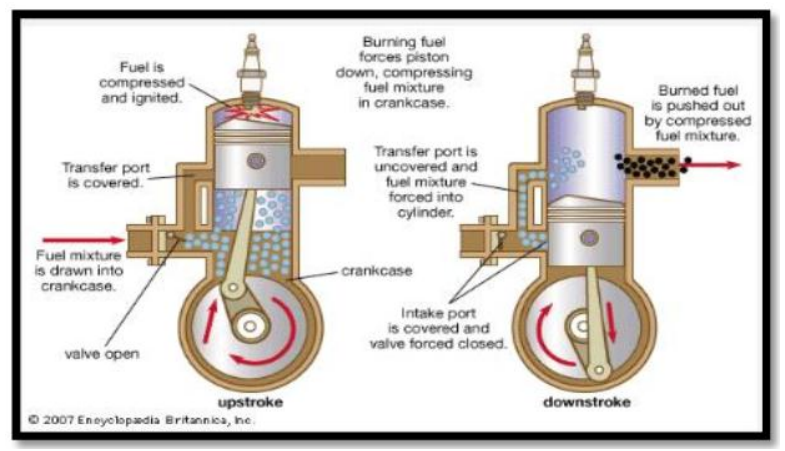

Gambar 1 Kerja Mesin 2-Tak

\section{Konsumsi Bahan Bakar}

Konsumsi bahan bakar kendaraan semakin menjadi perhatian mengingat harga bahan bakar minyak sebagai bahan bakar utama kendaraan semakin meningkat harganya. Di Indonesia, bahan bakar minyak untuk kendaraan sebagian besar diproduksi oleh PT Pertamina berupa premium dan solar. Bahan bakar bensin produksi Pertamina terdiri dari Premium, Pertamax maupun Pertamax Plus yang mempunyai kandungan nilai oktan berbeda, masing-masing RON 88, RON 91 dan RON 95. Angka oktan pada bahan bakar digunakan sebagai pedoman untuk mengatur periode penundaan (delay period) waktu nyala api busi untuk merambat ke bagian yang paling jauh dari busi. Bensin dengan angka oktan yang tinggi mempunyai periode penundaan yang panjang [2]. Namun demikian, penggunaan bahan bakar dengan angka oktan yang tinggi tidak memberikan perbaikan effisiensi dan daya jika digunakan untuk mesin yang dirancang untuk menggunakan bahan bakar dengan bilangan oktan yang rendah [3]. Penggunaan bahan bakar berdasarkan perbandingan kompresi. Rasio kompresi menunjukkan berapa jauh campuran udara dan bahan bakar yang dihisap selama langkah hisap dikompresikan dalam silinder selama langkah kompresi. Dengan kata lain adalah perbandingan dari silinder dan volume ruang bakar dengan piston pada posisii TMB (V2) dengan volume ruang bakar dengan torak TMA (V1). Rasio kompresi bisa dimodifikasi menjadi lebih rendah maupun lebih tinggi dengan dua cara yaitu merubah volume ruang bakar dan volume langkah piston. Penambahan volume ruang bakar akan mengakibatkan rasio kompresi menjadi lebih rendah, sebaliknya pengurangan ruang bakar mengakibatkan rasio kompresi menjadi lebih tinggi. Penambahan volume langkah piston akan mengakibatkan rasio kompresi menjadi lebih tinggi, sebaliknya pengurangan langkah piston mengakibatkan rasio kompresi menjadi lebih rendah. Rasio kompresi dan nilai oktan bahan bakar mempunyai hubungan yang erat. Bahan bakar premium dengan nilai oktan 88 cocok untuk rasio kompresi 7-9:1, pertamax dengan nilai oktan 92 cocok untuk rasio kompresi 9-10:1, dan pertamax plus dengan nilai oktan 95 cocok untuk rasio kompresi 10-11:1. [4]

Rasio kompresi dan nilai oktan bahan bakar berhubungan erat dengan emisi gas buang. Bahan bakar dengan oktan rendah sebaiknya menggunakan rasio kompresi yang rendah sedangkan bahan bakar dengan oktan tinggi sebaiknya menggunakan rasio kompresi yang lebih tinggi. Rasio kompresi yang sesuai dengan nilai oktan bahan bakar menghasilkan pembakaran yang sempurna, sehingga emisi yang dihasilkan juga menjadi lebih baik.

\section{Karburator \\ Unsur Dasar Karburator}

Tiga unsur yang menjadi dasar kerja karburator, yaitu tekanan atmosfir, kevakuman, dan prinsip kerja venturi. Tiga Unsur Dasar Kerja Karburator adalah:

1) Tekanan Atmosfir

Tekanan atmosfer adalah tekanan udara bebas disekitar kita, Tekanan udara ini akan selalu memenuhi setiap permukaan.

2) Vakum

Pengertian vakum yang sebenarnya adalah hampa, yaitu tidak ada udara sama sekali dalam suatu ruangan tertutup. Namun untuk lebih mudah dalam pemahaman kerja karburator, setiap tekanan yang lebih rendah dari tekanan atmosfer sebut dengan vakum atau tekanan rendah. Didalam motor saat piston bergerak 
menuju Titik Mati Atas (TMA), pada saat langkah kompresi pada silinder, akan menimbulkan tekanan rendah atau vakum pada ruang crankcase. Karena telah terjadi perbedaan tekanan antara ruang crankcase dengan udara bebas (tekanan udara bebas lebih tinggi), maka udara akan mengalir masuk kedalam crankcase melalui karburator

3) Venturi.

Perbedaan tekanan merupakan dasar kerja suatu karburator. Untuk mendapatkan suatu perbedaan tekanan didalam karburator, maka dibuatlah suatu penyempitan saluran udara di dalam karburator. Penyempitan saluran udara itu disebut "venturi “. Semakin cepat udara bergerak (mengalir) pada suatu venturi, maka akan semakin rendah tekanan udara pada saluran tersebut. Tekanan rendah inilah yang digunakan untuk menghisap bahan bakar dari ruang bahan bakar. Pada saluran yang tidak mengalami penyempitan akan mempunyai tekanan yang sama

\section{Konstruksi Karburator}

Seperti penjelasan sebelumnya ada beberapa macam karburator, salah satunya dipakai sesuai kegunaan dan baik untuk kondisi musim. Pada sepada motor Yamaha, karburator tipe VM dengan katup piston terutama dipakai pada mesin 2 (dua) langkah. Pada tipe VM, saluran bahan bakar dan udara berubah tergantung sejauh mana katup gas terbuka ditarik oleh tali gas seperti pada Gambar 2.[5]

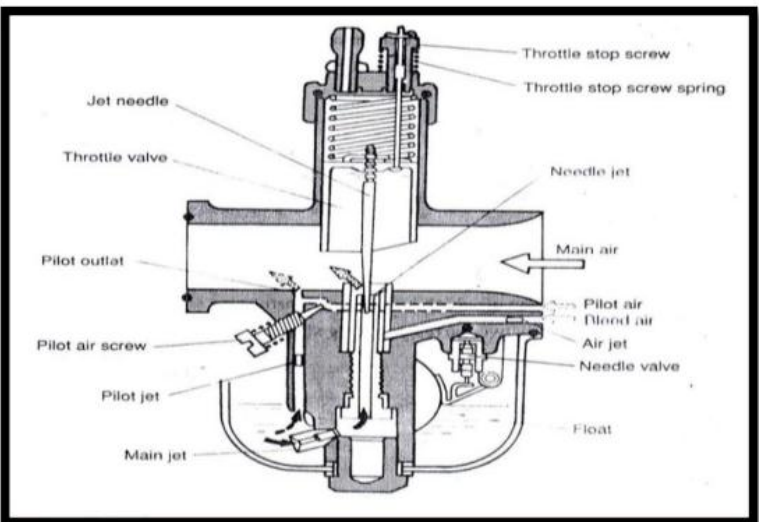

Gambar 2 Konstruksi Karburator

\section{METODOLOGI}

Konsep penelitian ini merupakan tahap awal dari pembuatan sebuah produk. Tahap ini yang akan menentukan hasil akhir dari sebuah analisa yang akan di lakukan hampir secara keseluruhan dalam penelitian ini, banyak hal-hal yang harus ditinjau terlebih dahulu. Untuk mempermudah langkah-langkah penelitian atau dalam proses analisa yang lebih teratur, maka dibuat diagram alir penelitian seperti pada Gambar 3.

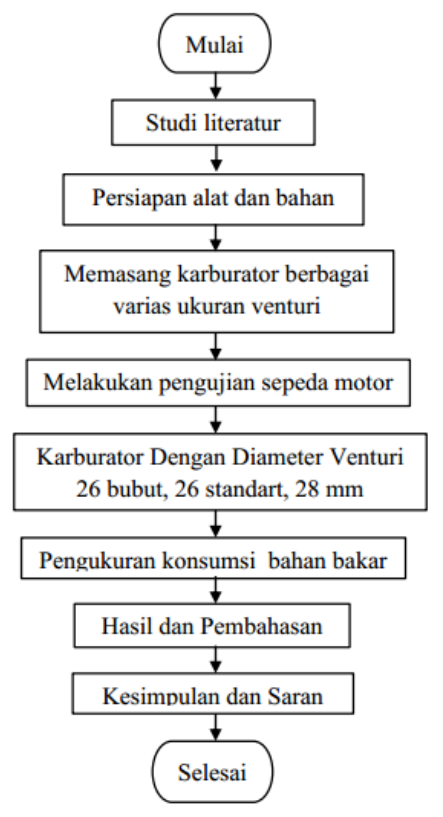

Gambar 3 Tahapan Penelitian

Adapun alat bantu dari proses penelitian adalah terdiri dari :

1. Sepeda Motor Yamaha RX-KING 135 cc tahun 2001.

2. Tangki Buatan

3. Obeng - dan + .

4. Tang

5. Gelas ukur

6. Manifol karet

7. Karburator ukuran venturi $26 \mathrm{~mm}$ standart, 26 mm bubut dan $28 \mathrm{~mm}$.

8. Keran bensin

9. Selang bensin

10. Tachometer

11. Jangka sorong

12. Termometer sensor

Bahan yang diperlukan adalah bahan bakar premium 5 liter dan engine oil 1 botol $800 \mathrm{ml}$ merek evalube pro sebagai pelumas pada mesin 2 tak.

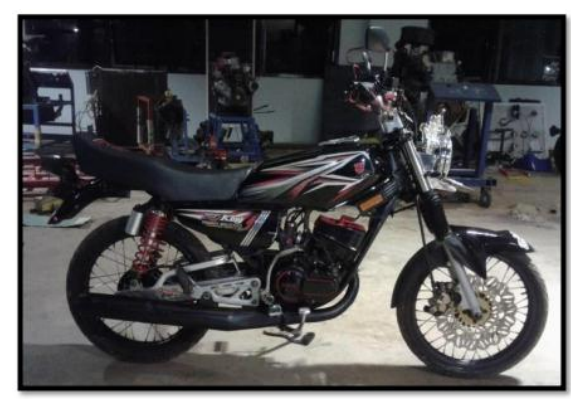

Gambar 4 Sepeda RX-King 
Diameter x Langkah : 59,0 x 50,0 mm

Volume Silinder : $136 \mathrm{cc}$

Susunan Silinder : Satu/Miring

Kopling : Manual, Basah, Multiplat

Gigi Transmisi : 5 Kecepatan

Pola Pengoperasian Gigi : 1-N-2-3-4-5

Rasio perbandingan tiap gigi : $1 \mathrm{st}=12 / 34$

: 2 nd $=16 / 30$

: $3 \mathrm{rd}=19 / 26$

: 4 th $=22 / 24$

: 5 th $=24 / 22$

Gigi Primer : 68/22

Gigi Skunder : $36 / 15$

Diameter efektif roda : $58,42 \mathrm{~cm}=0,5842 \mathrm{~m}$

Karburator : Mikuni VM 26

Kapasitas Oli Samping : 1 Liter

Busi : NGK T5999

Sistem Pengapian : CDI

Koil : Blue thunde

\section{Spesifikasi Karburator Uji}

Karburator yang dianalisa ada 3 macam dengan ukuran venturi yang berbedabeda seperti yang terlihat pada Gambar 5 yaitu karburator dengan ukuran venturi $26 \mathrm{~mm}$ proses pembubutan, $26 \mathrm{~mm}$ standart rx-king dan $28 \mathrm{~mm}$. Berikut penjelasan secara detail tentang spesifikasi karburator yang akan di analisa.

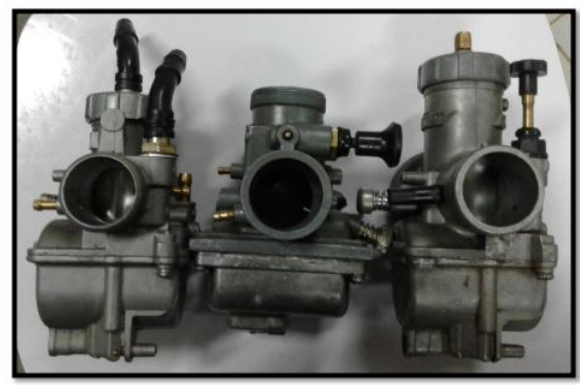

Gambar 5 Venturi Karburator

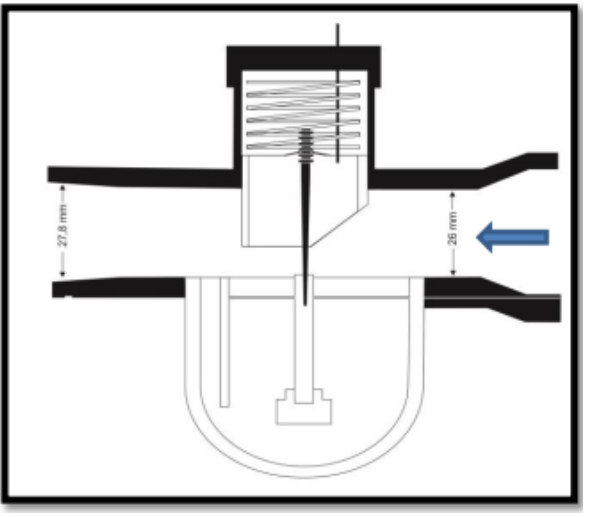

Gambar 6 Diameter Venturi Karburator
Seperti pada Gambar 6, adapun spesifikasi venturi pada karburator yang dibongkar dan diukur:

Pilot jet : 35

Main jet : 110

Skep : Bulat original

Tinggi pelampung : $23-25 \mathrm{~mm}$

Power jet : Tidak ada

Baut mangkok bawah : Ada

Venturi dalam : 27,8 mm

Jarum skep : Dapat diatur

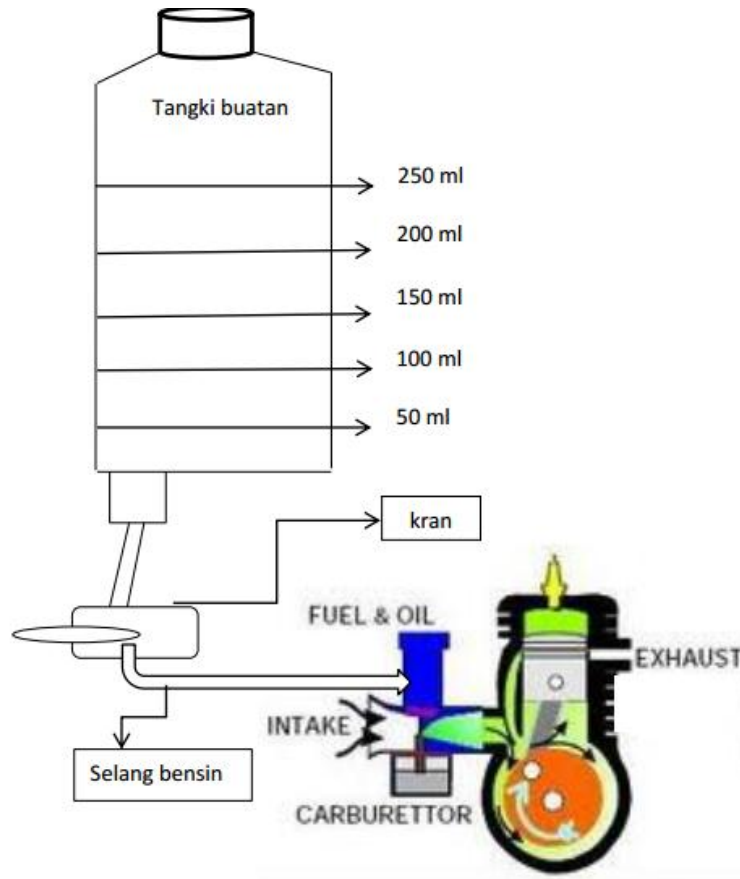

Gambar 7 Tangki Buatan

Seperti yang dilihat pada Gambar 6, adapun skema tangki bahan bakar buatan adalah mulai dari tangki bahan bakar yang disambungkan menggunakan selang ke kran bensin yang berfungsi mengatur buka tutupnya aliran bahan bakar dari tangki ke karburator.

Pengujian konsumsi bahan bakar (offroad test) atau stasioner dengan kondisi motor menggunakan variasi ukuran venturi karburator adapun pengujian ini dilakukan untuk melihat konsumsi bahan bakar yang digunakan pada kondisi diam (stasioner) pada sepeda motor yamaha Rx-king yang menggunakan karburator dengan ukuran venturi $26 \mathrm{~mm}$ bubut dan $28 \mathrm{~mm}$ dengan sepeda motor yamaha rx-king yang menggunakan karburator standardnya ukuran venturi $26 \mathrm{~mm}$. Persiapan pertama yang dilakukan adalah memanaskan mesin sampai $60{ }^{\circ} \mathrm{C}$ agar kondisi mesin di saat pengujian sudah optimal . Kemudian putar setelan gas di bagian karburator untuk menentukan putaran mesin yang dipakai dalam pengujian. Putaran mesin yang dipakai pada pengujian ini yaitu $4000 \mathrm{rpm}$ yang sudah dihitung dan dikonversikan dengan rumus sehingga kurang lebih sama dengan kecepatan sepeda motor $54 \mathrm{~km} / \mathrm{jam}$ di gigi 5 . Pengujian dimulai dengan 
mengisi bahan bakar pada tangki buatan sebanyak 100 ml yang mana bahan bakar tersebut telah diukur terlebih dahulu melalui gelas ukur. Selanjutnya sambungkan selang kekarburator uji yang sudah terpasang, setelah itu mesin dihidupkan dengan menghitung waktu pengujian menggunakan stopwatch sampai mesin mati . Setelah mesin mati stopwatch dinon-aktifkan kemudian catat waktu yang didapat pada pengujian tersebut.

\section{Prosedur pengujian :}

a. Siapkan sepeda motor yang akan dipakai

b. Pasang karburator yang akan di Analisa

c. Hidupkan mesin terlebih dahulu sehingga mencapai suhu kerja mesin $60^{\circ} \mathrm{c}$.

d. Karburator yang akan di analisa sebelumnya sudah dimodifikasi pada bagian pilot jet, main jet dan ketinggian jarum skep yang sudah disamakan ukurannya.

e. Pasang tangki buatan berkapasitas $250 \mathrm{ml}$

f. Sambungkan selang bensin dari tangki buatan kekarburator

g. Isi tangki bahan bakar buatan menggunakan premium dengan takaran $100 \mathrm{ml}$

h. Mulai pengujian stasioner dengan putaran mesin $4000 \mathrm{rpm}$ atau kurang lebih setara $54 \mathrm{~km} /$ jam di gigi 5

i. Hasil konsumsi bahan bakar dari setiap ukuran venturi dicatat, dihitung dengan rumus yang ada dan kemudian akan dikonversikan ke jarak tempuh dan waktu tempuh dari sekon (s) ke menit (min).

j. Menggunakan rumus perhitungan reduksi putaran untuk mengkonversi $4000 \mathrm{rpm}=54$ $\mathrm{km} / \mathrm{jam}$.

k. Rumusan reduksi total $(\mathrm{i})=$

$$
i=\frac{z 2}{z 1} x \frac{z 4}{z 3} x \frac{z 6}{z 5}
$$

\section{Dimana:}

$\frac{z 2}{z 1}=$ reduksi primer

$\frac{z 4}{z 3}=$ perbandingan gigi transmisi

$\frac{z 6}{z 5}=$ perbandingan reduksi sekunder

Seperti terlihat pada Gambar 8, reduksi primer dengan shaft piston terhadap kopling, yang terhubung dengan poros roda gigi yang bervariasi sesuai tingkat kecepatan sepeda motor. Kemudian reduksi sekunder dari putaran mesin ke gear roda belakang yang terhubung dengan transmisi (rantai)



Gambar 8 Sistem Reduksi Roda Gigi

1. Rumusan kecepatan

$$
\operatorname{Kecepatan}(v)=\frac{60, \pi_{\mathrm{m}} / \pi_{\mathrm{s}} P \cdot n}{1000 \cdot i}
$$

Dimana:

$$
\begin{aligned}
\mathrm{D} & =\text { diameter efektif roda }(\mathrm{m}) \\
\mathrm{n} & =\text { putaran mesin }(\mathrm{rpm}) \\
\mathrm{i} & =\text { reduksi total }
\end{aligned}
$$

m. Rumusan waktu tempuh

$$
\text { Jarak tempuh }(s)=v \cdot t \quad(\mathrm{~km})
$$

$$
\begin{aligned}
\text { Dimana: } & \\
\mathrm{v} & =\text { kecepatan }(\mathrm{km} / \mathrm{jam}) \\
\mathrm{t} & =\text { waktu tempuh }(\mathrm{jam})
\end{aligned}
$$

\section{HASIL DAN PEMBAHASAN}

Hasil yang didapat dari penelitian berupa data waktu yang ditabulasikan pada tabel kemudian menghasilkan rata-rata. Data rata-rata yang didapat nantinya juga akan dikonversikan ke jarak tempuh tidak hanya pada hasil waktu saja. Adapun data yang diperoleh adalah data konsumsi bahan bakar dalam satuan waktu per $100 \mathrm{ml}$ pada putaran mesin $4000 \mathrm{rpm}$ atau setara 54 $\mathrm{km} / \mathrm{jam}$. Untuk mengetahui $54 \mathrm{~km} / \mathrm{jam}$ sebelumnya melakukan perhitungan sebagai berikut.

\section{Diketahui: :}

Perbandingan reduksi primer rx-king adalah $68 / 22$ Perbandingan gigi trasmisi pada gigi 5 adalah 24/22 Perbandingan reduksi sekunder yang digunakan 36/15 Diameter efektif roda $58,42 \mathrm{~cm}=0,5842 \mathrm{~m}$ Rpm yang diteliti 4000

$$
i=\frac{68}{22} x \frac{24}{22} x \frac{36}{15}
$$

sehingga didapat 8,09247, denganrumus kecepatan didapat $\mathrm{v}=54,402 \mathrm{~km} / \mathrm{jam}$. 


\begin{tabular}{|c|c|c|c|c|c|}
\hline \multirow[t]{2}{*}{ No } & \multirow{2}{*}{$\begin{array}{l}\text { Put } \\
\text { (rpm) }\end{array}$} & \multirow{2}{*}{$\begin{array}{l}\text { Bahan bakar } \\
\quad(\mathrm{ml})\end{array}$} & \multicolumn{3}{|c|}{$\begin{array}{l}\text { waktu (s) } \\
\text { ukuran venturi }\end{array}$} \\
\hline & & & $\begin{array}{l}26 \mathrm{~mm} \\
\text { standart }\end{array}$ & $\begin{array}{c}26 \mathrm{~mm} \\
\text { bubut }\end{array}$ & $28 \mathrm{~mm}$ \\
\hline 1 & \multirow{10}{*}{4000} & \multirow{10}{*}{100} & 432 & 517 & 355 \\
\hline 2 & & & 425 & 512 & 379 \\
\hline 3 & & & 429 & 500 & 352 \\
\hline 4 & & & 424 & 501 & 357 \\
\hline 5 & & & 438 & 505 & 366 \\
\hline 6 & & & 426 & 503 & 358 \\
\hline 7 & & & 430 & 504 & 372 \\
\hline 8 & & & 427 & 513 & 380 \\
\hline 9 & & & 429 & 520 & 374 \\
\hline 10. & & & 428 & 518 & 379 \\
\hline \multicolumn{3}{|c|}{ Jumlah } & 4288 & 5093 & 3690 \\
\hline \multicolumn{3}{|c|}{ Rata-rata detik } & 428.8 & 509.3 & 369 \\
\hline \multicolumn{3}{|c|}{ Rata- rata menit } & 7.14 & 8.48 & 6.15 \\
\hline
\end{tabular}

Tabel 1 Data Hasil Pengujian

Seperti terlihat pada Tabel 1, dapat dibuat grafik hubungan besarnya diameter venturi terhadap waktu yang dibutuhkan untuk menghabiskan $100 \mathrm{~mL}$ bahan bakar, dengan pengambilan 10 data tiap percobaan kemudian di rata-rata. Setting karburator dan prosedur yang sama, yang berbeda hanya diameter venturinya saja, perbandingan itu terlihat pada Gambar 9.

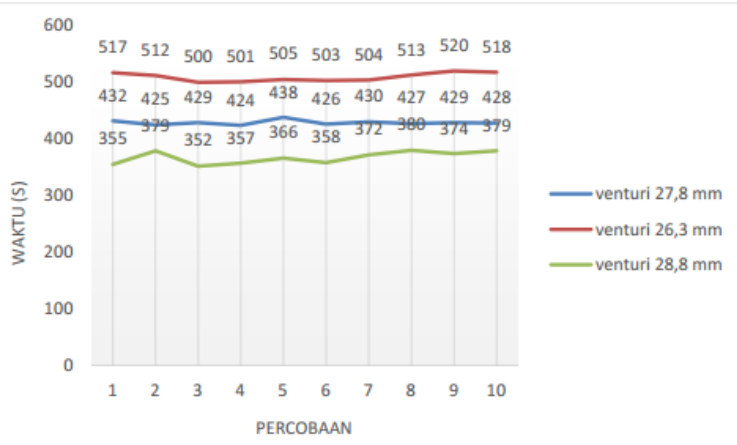

Gambar 9 Grafik Hubungan Venturi dan Waktu Dengan Percobaan 10x

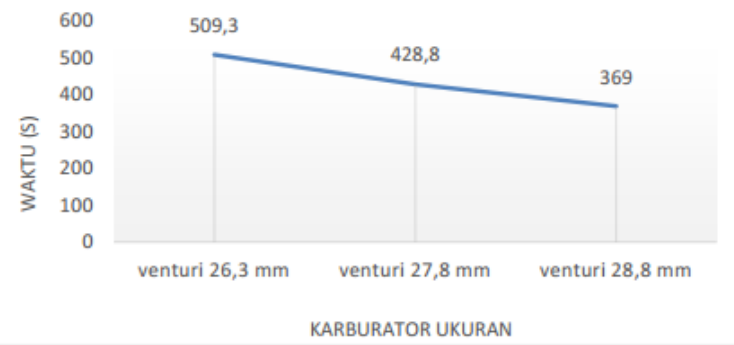

Gambar 10 Hubungan Venturi vs Waktu Rata-rata

Pada Gambar 10 merupakan diagram grafik hubungan antara variasi diameter venturi pada karburator terhadap konsumsi bahan bakar pada sepeda motor Yamaha Rx-king 135cc tahun 2001. Grafik tersebut diperoleh berdasarkan hasil penelitian, pada grafik tersebut dapat diamati konsumsi bahan bakar yang paling rendah adalah pada diameter venturi 26,3 $\mathrm{mm}$ yaitu dengan rata-rata waktu yang didapat pada 100 $\mathrm{ml}$ bahan bakar dalam putaran mesin $4000 \mathrm{rpm}$ dengan kecepatan aliran bahan bakar yang masuk kedalam ruang bakar 157,99 (m/s) adalah 509,3 detik atau bila dikonversikan ke jarak tempuh mendapat 7,632 km lebih lama dan jauh dibandingkan konsumsi bahan bakar pada karburator ukuran standart rx-king 27,8 mm dengan kecepatan aliran bahan bakar sebesar 150,22 $(\mathrm{m} / \mathrm{s})$ yang hanya mampu memperoleh waktu 428,8 detik atau $6,426 \mathrm{~km}$ dan pada diameter venturi $28,8 \mathrm{~mm}$ yaitu dengan rata-rata waktu yang didapat pada $100 \mathrm{ml}$ bahan bakar dalam putaran mesin sebesar $4000 \mathrm{rpm}$ serta kecepatan aliran bahan bakar 159,54 (m/s) yang hanya mendapat 369 detik atau $5,535 \mathrm{~km}$.

Tentunya semua hasil yang didapat kembali kepada ukuran diameter venturi. Walaupun kecepatan aliran pada venturi pada karburator standart rx-king lebih lambat dari pada kecepatan aliran karburator hasil pembubutan, namun konsumsi bahan bakarnya tetap lebih tinggi dikarenakan ukuran venturi standart rx-king lebih besar $1,5 \mathrm{~mm}$ dari pada karburator pembubutan. karburator standart rx king ukuran venturinya $27,8 \mathrm{~mm}$ sedangkan karburator pembubutan ukuran venturinya $26,3 \mathrm{~mm}$. sedangkan pada karburator ukuran venturi $28,8 \mathrm{~mm}$ konsumsi bahan bakar paling besar dikarenakan kecepatan alirannya paling tinggi dan lebih banyak lagi campuran udara dan bahan bakar yang masuk, dikarenakan ukuran venturinya juga yang lebih besar dan moncong karburator yang lebih besar dari karburator standart rx-king dan karburator hasil pembubutan sehingga udara yang terisap masuk lebih banyak dan mudah mengangkat bahan bakar yang ada di dalam karburator.

Konversi satuan detik ke menit, dari berbagai hasil penelitian diameter venturi 26,$3 ; 27,8 ; 28,8 \mathrm{~mm}$ berturut-turut adalah 8,48 menit; 7,14 menit; dan 6,15 menit. dengan hasil ini maka konsumsi venturi karburator kecil lebih lama (irit) dari yang venturi 
karburator standart dengan perbandingan $18,77 \%$. Hal ini tanpa mengurangi performa dari mesin sepeda motor RX-king.

\section{KESIMPULAN}

Berdasarkan hasil penelitian didapat pengaruh perbedaan ukuran venturi terhadap konsumsi bahan bakar sebagai berikut :

1. Konsumsi bahan bakar dari karburator ukuran venturi $26 \mathrm{~mm}$ standart rx-king pada setiap $100 \mathrm{ml}$ bahan bakar dan putaran mesin $4000 \mathrm{rpm}$ adalah selama 7,14 menit atau jarak tempuh $6.426 \mathrm{~km}$ dan pada karburator ukuran venturi $26 \mathrm{~mm}$ pembubutan adalah 8.48 menit atau jarak tempuh $7.632 \mathrm{~km}$ sedangkan pada ukuran venturi $28 \mathrm{~mm}$ adalah 6.15 menit atau jarak tempuh $5.535 \mathrm{~km}$.

2. Konsumsi bahan bakar terendah dari variasi ukuran venturi karburator adalah pada karburator venturi $26 \mathrm{~mm}$ bubut dengan hasil 8.48 menit atau jarak tempuh $7.632 \mathrm{~km}$.

3. Konsumsi bahan bakar tertinggi dari variasi ukuran venturi karburator adalah pada karburator venturi $28 \mathrm{~mm}$ dengan hasil 6.15 menit atau jarak tempuh $5.535 \mathrm{~km}$.

4. Efektivitas penurunan konsumsi bahan bakar dari venturi yang diperkecil dibawah standart adalah sebesar $18,77 \%$.

\section{DAFTAR PUSTAKA}

[1] Kristanto, Philip., 2015c. Motor Bakar Torak. ANDI Yogyakarta.

[2] Hartono, T., 2011. Penelitian Pengaruh Penggunaan Bahan Bakar Premium, Pertamax dan Pertamax Plus Terhadap Unjuk Kerja Motor Bakar Bensin. FT, Universitas Muhammadiyah Surakarta.

[3] Arismunandar, W., 1988. Penggerak Mula Motor Torak. Bandung, ITB press.

[4] Sriyono, Amay .S. Pengujian Modifikasi Diameter Venturi Terhadap Presentasi motor. Torsi, vol 8, No.1, Januari 2010

[5] UPT Pelatihan Kerja. 2009. Sistem Bahan Bakar Konvensional. Mojokerto.

[6] Sujono, Santoso, H. 2014. Pengaruh Variasi mainJet Karburator Pada Motor Bakar BioEtanol. Vol 12, No. 3.

[7] Sudik. 2013. Perbandingan Performa Dan Konsumsi Bahan Bakar Motor Diesel Satu Silinder Dengan Variasi Tekanan Injeksi Bahan Bakar Dan Variasi Campuran Bahan Bakar Solar, Minyak Kelapa Dan Minyak Kemiri. Fakultas Teknik Universitas Negeri Semarang.

[8] Purnomo, Triono Bagus. 2013. Perbedaan Performa Motor Berbahan Bakar Premium 88
Dan Motor Berbahan Bakar Pertamax 92. Fakultas Teknik,Universitas Negeri Semarang 